\title{
Generalized Absence Epilepsy and Catalepsy in Rats
}

\author{
GALINA D. KUZNETSOVA,* ELENA V. PETROVA,* ANTON M. L. COENEN $\dagger$ AND \\ EGIDIUS L. J. M. VAN LUIJTELAAR $\dagger^{+1}$
}

\author{
*Institute of Higher Nervous Activity and Neurophysiology, Russian Academy of Sciences, Moscow, Russia and \\ †NICI, Department of Psychology, University of Nijmegen, Nijmegen, The Netherlands
}

\author{
Received 25 October 1995
}

\begin{abstract}
KUZNETSOVA, G. D., E. V. PETROVA, A. M. L. COENEN AND E. L. J. M. VAN LUIJTELAAR. Generalized absence epilepsy and catalepsy in rats. PHYSIOL BEHAV 60(4) 1165-1169, 1996. - Adult WAG/Rij rats are considered adequate genetic models for human generalized absence epilepsy. Rats of this strain of 8,12 , and 18 weeks old and age-matched control Wistar rats were exposed to sound stimulation. After offset of stimulation, all WAG/Rij rats showed cataleptic or even cataplexic reactions, which could persist for up to $20 \mathrm{~min}$. Age effects could be demonstrated. None of the Wistar rats showed cataleptic reactions. Electroencephalographic studies in WAG/Rij rats of 21 weeks showed that spike-wave discharges were abundantly present in the background electroencephalogram prior to sound stimulation. Age-matched Wistar rats had almost no spike-wave discharges. Spike-wave discharges in WAG/Rij rats disappeared during sound stimulation and were then increased compared to the prestimulation and stimulation periods. The electroencephalogram during the cataleptic state was also characterized by the presence of large amplitude $2 \mathrm{~Hz}$ waves, interspersed with spike-wave discharges. The data suggest that the cataleptic state can be elicited in genetically epilepsy-prone rats. The youngest WAG/Rij rats showed no spike-wave discharges during the cataleptic state. In all, the data suggest that epilepsy-prone animals are sensitive for catalepsy at an age at which the EEG signs of generalized absence epilepsy are not yet manifest.
\end{abstract}

Absence epilepsy Catalepsy Spike-wave discharges WAG/Rij rats Slow wave activity Age Gender

A CATALEPTIC state can be induced in animals such as rabbits and rats by the manipulation of the animal's body into an awkward or unnatural posture, temporarily sustained by imposing restraint $(16,17,18,19)$. Sometimes this state coincides with epilepsy and, especially in animal models, this relationship is sometimes found $(21,23,26)$. In Krushinsky-Molodkina (KM) rats, a genetic model of sound-induced tonic-clonic seizures, convulsions are followed by long phases of immobility, which closely resemble the cataleptic state (21). Myslobodsky et al. (23) found that catalepsy occurred in varying degrees in rats after maximal electroshock, and after application of metrazol or picrotoxin. Petrova et al. (26) described genetically cataleptic rats $(17,18,19)$ that showed an increased predisposition to epileptiformic activity, including spike-wave activity. Symptoms associated with catalepsy are also not rare in epileptic patients. Loiseau (22) observed that absence fits in children are accompanied by cataleptic reactions in $20 \%$ of cases.

However, the relationship between catalepsy and absence epilepsy has been only minimally investigated in genetic types of animal models. The inbred strain of WAG/Rij rats (27), a selection line of rats such as the GAERS (30), and several outbred strains of Wistars (29), show spontaneously occurring generalized spike-wave discharges (6). These genetically determined spike-wave discharges are accompanied by minor clinical signs, including facial myoclonus (25). Otherwise, the animal is immobile. Spike-wave discharges predominantly occur during passive wakefulness and light slow-wave sleep, and at transitions from sleep to awake and vice versa (9). Pharmacological studies have demonstrated that spike-wave discharges can by suppressed by typical anti-absence and by broad spectrum anti-epileptic drugs, but not by the typical anticonvulsants (24). Considering the presumed association between catalepsy and generalized epilepsies and, more particularly, absence epilepsy, the sensitivity for catalepsy was investigated in a model for a nonconvulsive type of epilepsy, the WAG/Rij rats, and compared with that in outbred Wistar rats.

\section{METHODS}

Male $(n=26)$ and female $(n=11)$ WAG/Rij rats that were 8,12 , and 18 weeks old and male $(n=15)$ Wistar rats 9 and 19 weeks old, varying in body weights between 100 and $355 \mathrm{~g}$, were used for the behavioural study. They were born and raised at the Institute of Higher Nervous Activity and Neurophysiology in Moscow. Rats were housed under a natural light-dark regimen with 5 to 6 animals per cage.

\footnotetext{
${ }^{1}$ Requests for reprints should be addressed to Dr. E. L. J. M. van Luijtelaar, NICI, Department of Psychology, University of Nijmegen, P. O. Box 9104, 6500 HE Nijmegen, The Netherlands. E-mail:luijtelaar@nici.kun.nl
} 
TABLE 1

CHARACTERISTICS AND CATALEPTIC REACTIONS (MEANS AND SEM) IN WISTAR AND WAG/RIJ RATS AS DETERMINED BEFORE, 1 AND 5 MIN AFTER SOUND STIMULATION

\begin{tabular}{|c|c|c|c|c|c|c|c|}
\hline \multirow[b]{2}{*}{ Age (weeks) } & \multicolumn{2}{|c|}{ Wistar } & \multirow[b]{2}{*}{8} & \multicolumn{3}{|c|}{ WAG/Rij } & \multirow[b]{2}{*}{18} \\
\hline & 9 & 19 & & 8 & 8 & 12 & \\
\hline Sex & $\mathbf{M}$ & $\mathbf{M}$ & $\mathbf{M}$ & $\mathrm{F}$ & $\mathrm{M} / \mathrm{F}$ & M & $\mathrm{M}$ \\
\hline Body Weight (grams) & 140 & 250 & 130 & 100 & $100-130$ & 180 & 240 \\
\hline $\mathrm{n}$ & 10 & 5 & 11 & 11 & 22 & 5 & 10 \\
\hline \multicolumn{8}{|l|}{ Cataleptic Reaction } \\
\hline before stim & $0 \pm 0$ & $0 \pm 0$ & $0.02 \pm 0.1$ & $0.01 \pm 0.1$ & $0.02 \pm 0.0$ & $0 \pm 0$ & $0.0 \pm 0$ \\
\hline 1 min after stim & $0 \pm 0$ & $0 \pm 0$ & $2.0 \pm 0.3$ & $1.4 \pm 0.3$ & $1.7 \pm 0.2$ & $2.4 \pm 0.2$ & $2.6 \pm 0.2$ \\
\hline $\begin{array}{l}5 \text { min after stim } \\
\text { difference }(5-1 \mathrm{~min}\end{array}$ & $0 \pm 0$ & $0 \pm 0$ & $2.9 \pm 0.1$ & $2.5 \pm 0.3$ & $2.7 \pm 0.1$ & $2.8 \pm 0.2$ & $2.8 \pm 0.1$ \\
\hline after stim) & $0 \pm 0$ & $0 \pm 0$ & $0.9 \pm 0.3$ & $1.2 \pm 0.3$ & $1.1 \pm 0.2$ & $0.4 \pm 0.2$ & $0.2 \pm 0.1$ \\
\hline duration (min) & $0 \pm 0$ & $0 \pm 0$ & $12 \pm 1$ & $8.7 \pm 1$ & $10.4 \pm 0.8$ & $18.2 \pm 1.6$ & $15.1 \pm 1.1$ \\
\hline
\end{tabular}

Independent age groups were used. The data of the 8-week-old male and female rats are presented separately and combined.

The experiment took place in freely moving animals in a wooden box of $40 \times 40 \mathrm{~cm}$ during the light phase of the 24-h LD cycle, between 1600 and $1800 \mathrm{~h}$. Complex sound stimuli were produced by a bunch of keys ringing for $2 \mathrm{~min}$. This procedure has traditionally been used by a number of authors to test audiogenic sensitivity in rats (21). These sounds have a complex frequency spectrum, with frequencies varying between 13 and 80 $\mathrm{kHz}$. The mean loudness level is about $60 \mathrm{dBA}$ and there are multiple peaks of up to $90 \mathrm{dBA}$.

The 3 groups of WAG/Rij rats were compared with 2 groups of Wistar rats, 9 and 19 weeks old, for their reaction toward sound stimulation. The cataleptic state was assessed before, and 1 and $5 \mathrm{~min}$ after the end of sound presentation. The duration and the depth of cataleptic postures was measured. The depth or the intensity of the cataleptic state was determined based on a procedure developed by Kostowsky et al. (20) and Kolpakov et al. (18). In brief, at the time points mentioned, we tried to put the rat into a vertical position near a wall of the wooden box or to have it seated on its sacrum in one of the corners of the box. If this was not successful, it was repeated at the next time point. The reaction of the animal was scored as: $0=$ no catalepsy, $1=$ the rat retains its vertical position for $1 \mathrm{~min}$ but does not sit on its sacrum, 2 = the rat sits on its sacrum for 1 to $5 \mathrm{~min}$, and $3=$ a rat retains its sitting position for more than $5 \mathrm{~min}$.

Three electrophysiological studies were performed. In the first study, 5 male WAG/Rij rats, 10 weeks old; in the second study, 25 male WAG/Rij rats, 20 weeks old; and, in the third study, 30 male Wistar rats, 20 weeks old, were used. Until surgery, they lived with 3 animals per cage; after surgery, they were singly housed. Rats were provided, under Nembutal anaesthesia (40 $\mathrm{mg} / \mathrm{kg}$ ), with 3 to 8 permanent epidural EEG electrodes. Following surgery, subjects were allowed to recover for 5 to 7 days. Cortical EEG traces, filtered between 1.5 and $70 \mathrm{~Hz}$, were recorded on a Bioscript BST 2000 or on a PC with the aid of the ACODAS system. EEGs were analyzed offline.

In the first electrophysiological study, 5 young WAG/Rij rats were exposed to 2-min sound stimulation while the EEG was recorded, followed by the assessment of the cataleptic state. In the now 21-week-old WAG/Rij rats, the EEG was recorded before, during, and after presentation of the sound stimuli. Control EEGs were made of Wistar rats, always in the light period between 1600 and $1700 \mathrm{~h}$.

The number and duration of spike-wave discharges were determined according to criteria elaborated elsewhere (27). The percent of total time with spike-wave discharges was calculated and expressed in a Spike-Wave-Index (SW-Index).

A presumed relation between catalepsy and age was analyzed, with a one-factor (age) ANOVA, gender differences with a $t$-test for independent variables, dynamics of catalepsy with difference scores ( $t$-test for dependent variables), and differences in dynamics among rats of different ages with a one-factor (age) ANOVA.

\section{RESULTS}

Wistar and WAG/Rij rats were compared with respect to their behavioural response toward sound stimulation. Before stimulation, WAG/Rij rats tended to be more passive and showed less locomotor activity than Wistar rats. One single WAG/Rij rat showed a cataleptic sign; none of the Wistar rats did. During sound stimulation, Wistar rats showed signs of anxiety such as grooming, but also rearing and searching reactions were observed. WAG/Rij rats showed the typical head swaying and displayed less locomotor activity than Wistar rats; grooming and rearing behaviour were absent.

Table 1 summarizes all the catalepsy data and, from this table, it can be inferred that none of the Wistar rats showed any cataleptic reaction, in strong contrast to the WAG/Rij rats. The latter rats, of all age groups, showed cataleptic reactions that reactions were already present 1 min after offset of sound stimulation. At this phase, rats generally retained the imposed posture "standing at the wall" or "sitting on the sacrum" in the corner of the box. The latter state is definitely an unusual posture for the animal. The cataleptic state was more intense at the next measure point because the difference score turned out be significant for the youngest groups ( $t$ s for male and female rats were both $3.6, d f$ $=10, p \mathrm{~s}<0.01$ ).

Gender differences in catalepsy in the WAG/Rij strain were not found. Only a tendency $(p<0.06)$ was present: males tended to have a longer duration of cataleptic behaviour than females.

Age effects in catalepsy were present. The duration of cataleptic reactions was longer and the intensity was increased in older WAG/Rij rats, compared to the youngest group. Indeed, a significant age effect was found for the first ( 1 min after stimulation) catalepsy scores $(F(2,34)=4.25, p<0.05)$, for the difference between the second and the first catalepsy score $(F(2,34)=4.33, p<0.05)$, and for the total duration of the cataleptic state $(F(2,34)=10.86, p<0.001)$. Post hoc tests, according to Duncan, showed that 18 -week-old WAG/Rij rats 


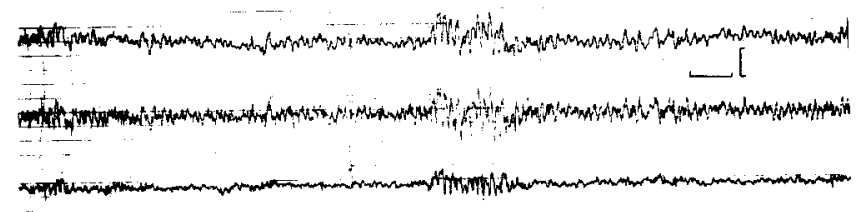

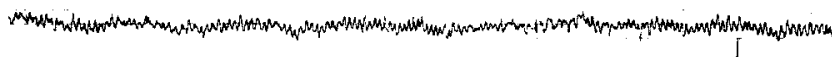
A
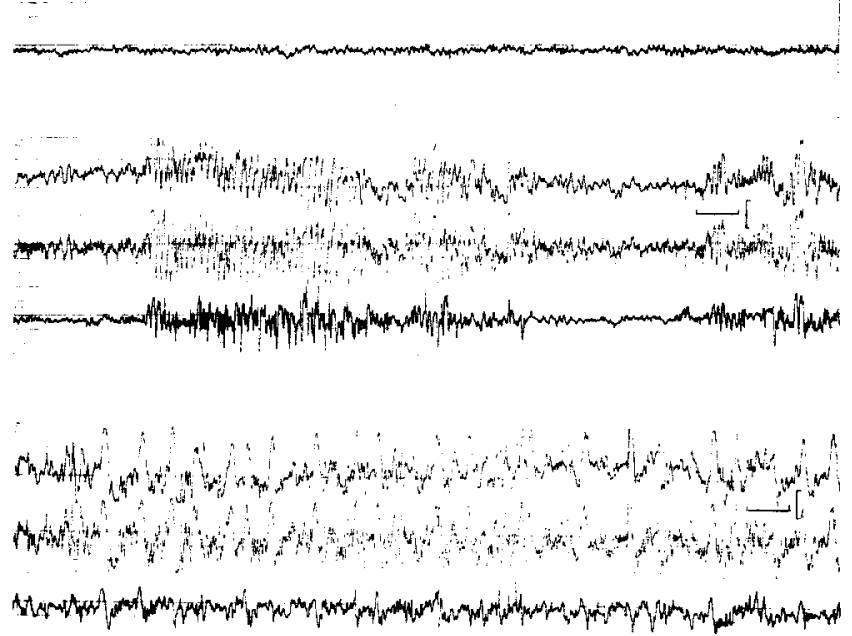

FIG. 1. Example of a cortical electroencephalogram of a WAG/Rij rat before (upper 3 tracings), during, and after (lower 2 tracings) audiogenic stimulation. Note the presence of theta rhythm during stimulation and slow waves in the bottom EEG tracing (poststimulation). Calibration: 1 s and $200 \mu \mathrm{V}$.

scored higher than 8-week-old rats on the catalepsy score. Moreover, the difference score was larger for young than for the oldest rats. This suggests a difference in dynamics of catalepsy in young and older rats. Finally, the duration of the cataleptic state was longer for 12- and 18-week-old subjects compared to the youngest group. In some WAG/Rij rats, the duration of cataleptic behavior lasted up to $20 \mathrm{~min}$. During this long-lasting imposed immobility, it was sometimes observed that stretched paws slowly dropped, suggesting that the muscle tone decreased. This can be an indication that catalepsy changed into cataplexy.

Visual analysis of the EEG recordings was made before, during, and after audiogenic stimulation in WAG/Rij rats, and a representative individual EEG recording is presented in Fig. 1. Figure 2 illustrates the mean number of spike-wave discharges at the various phases of the experiment. There were less spikewave discharges during audiogenic stimulation, as was revealed during paired $t$-tests comparing SW-index during and prestimulation $(t(25)=11.71, p<0.0001)$, and during and poststimulation $(t(25)=-9.76, p<0.0001)$. The number of spike-wave discharges was also higher after stimulation compared to the prestimulation period $(t(25)=-11.8, p<0.0001)$. In short, it was found that spike-wave discharges were present before stimulation, disappeared during stimulation, and were increased after stimulation.

It was also noticed that large amplitude slow waves emerged in the EEG during the cataleptic state. They appeared 10 to 15 min after the offset of sound stimulation. These large waves were present in both hemispheres, and were generalized. They were not seen prior to sound stimulation and did not resemble nonREM sleep waves; they looked more stereotyped that what is commonly seen in nonREM sleep. In Fig. 1, this slow activity can be seen. Periods of large amplitude slow waves were interspersed with spike-wave discharges. A frequency analysis of the large slow waves showed that these had a mean frequency of 2 $\mathrm{Hz}$, whereas the amplitude was about half of the amplitude of the spikes of the spike-wave discharges. It seemed that the appearance of slow waves and spike-wave discharges concurred with the appearance and augmentation of cataleptic symptoms.

The spike-wave index in 21-week-old Wistar rats was $1.1 \pm$ 0.3 ; in age- and sex-matched WAG/Rij rats, this was $14.1 \pm 1.2$. Four of the five 10-week-old WAG/Rij rats showed catalepsy following audiogenic stimulation (range 2 to $15 \mathrm{~min}$ ); however, this was not accompanied by spike-wave discharges in the EEG. The animal with the longest duration of the cataleptic state showed large amplitude slow-wave activity during the cataleptic state. Wild running during sound stimulation was noticed in 3 rats, followed in 2 animals by tonic-clonic seizures. In all 3 young WAG/Rij rats, this was followed by an easy induction of the cataleptic state.

\section{DISCUSSION}

The most important finding of the present work is that stimuli commonly used for evoking audiogenic seizures (21), led to the development of catalepsy in WAG/Rij rats. Control Wistar rats were not sensitive for this type of audiogenic stimulation; they neither showed audiogenic seizures, nor signs of catalepsy. Finally, these control rats have a low incidence of spike-wave discharges, similar to what has been reported by others (15), in any case much lower than in WAG/Rij rats. In the latter strain, all subjects above 5 to 6 months of age show hundreds of spikewave discharges per day $(6,27)$. In all, these data suggest a relationship between the sensitivity for catalepsy and the presence of spike-wave discharges. Electrophysiological data from the

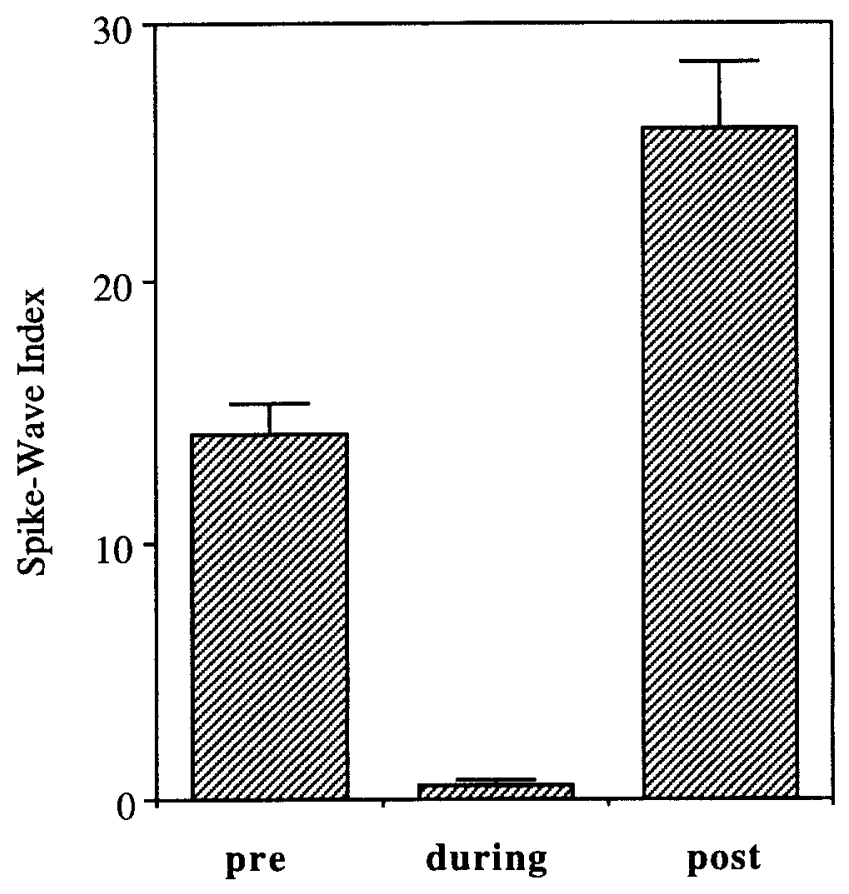

FIG. 2. Mean and SEM of spike-wave (SW) Index before, during, and after sound stimulation. 
oldest WAG/Rij rats supplement the behavioral changes after the offset of sound stimulation: spike-wave discharges and slow waves emerged in the EEG.

It has been extensively shown that the number of spike-wave discharges in WAG/Rij rats depends on the state of the animal $(5,9,10,28)$. A maximal expression of spike-wave discharges can be seen during periods of drowsiness and light slow-wave sleep, and spike-wave discharges tend to disappear during active wakefulness and REM sleep. Our experiments began when the animals were in a relaxed state of waking and spike-wave discharges were not rare. Sound stimuli induced an arousal reaction and spike-wave discharges disappeared; a phenomenon that was also noticed in periods of photostimulation (5), or during the execution of an operant learning task (28). After offset of the sound, catalepsy in WAG/Rij rats could be induced and this was gradually and slowly augmented, as expressed by higher catalepsy scores 5 min compared to $1 \mathrm{~min}$ after the sound offset. During the cataleptic state, a slow but significant augmentation of spike-wave discharges, together with the appearance of the slow EEG waves, was noticed. So, it seemed that, at least in the oldest group, the behavioral changes were accompanied by changes in the EEG. This also suggests a correspondence between catalepsy and spike-wave discharges. The different dynamics of catalepsy in young and older WAG/Rijs or the increase in the duration of the catalepsy found in older WAG/Rijs might be due to the presence of the aberrant EEG (spike-wave discharges and slow large waves) in older WAG/ Rij rats. The relation between catalepsy and spike-wave discharges was less clear in young WAG/Rij rats. At week 8 , the first age at which catalepsy was established, these rats do not show much spike-wave activity. EEG controlled studies in slightly older WAG/Rij rats established that 4 of the 5 rats showed catalepsy, and 1 of 4 showed the large slow waves. However, spike-wave discharges were not seen during the cataleptic state. The outcomes of this control experiment should be carefully considered, for the reason that wild running occurred in 3 and tonic-clonic seizures in 2 animals during audiogenic stimulation. If, however, the absence of spike-wave discharges during the cataleptic state in these young rats is representative, then it is possible that catalepsy in younger and older WAG/Rij rats occurs during a different background EEG. In any case, it needs to be stressed that the enhanced sensitivity for catalepsy is already present at an age in which the spikewave discharges are hardly present, neither during a base-line period (4), nor during the period of catalepsy, and it seems that the enhanced sensitivity for catalepsy preceeds the development of spontaneously occurring spike-wave discharges. Differences in ontogeny may weaken the relationship between spike-wave discharges and catalepsy. However, the possibility still cannot be excluded that the early sensitivity for catalepsy may cause the development of spike-wave discharges in this particular strain of rats.

A putative sex difference in the sensitivity for catalepsy was only evaluated for the youngest group. It was found that males tend to be more sensitive than females. The possibility cannot be excluded that, in older rats, similar or larger gender differences can be noticed. This points towards the role of gender and sex hormones in catalepsy. Gender and steroid effects in sensitivity for haloperidol-induced catalepsy have been reported: males are more sensitive for catalepsy than females, possibly because estradiol reduces catalepsy (12).

The mechanism for the induction of catalepsy is not clear, although pharmacological studies have indicated a role of some neurotransmitter systems in catalepsy. The best known system involved in catalepsy is the dopaminergic system. Antagonists at dopaminergic receptors, such as haloperidol, reliably induce catalepsy $(16,18)$. The amount of catalepsy is even considered as a reliable behavioral index for decreased dopaminergic transmission. There is little doubt that the anatomical locus of the induction of catalepsy by dopaminergic antagonists is the striatum (16). It is of interest that some of the dopamine antagonists strongly facilitate the number of spike-wave discharges in rat strains endowed with spike-wave discharges $(2,13,15)$. Administration of dopamine antagonists into the head of the caudate nucleus yields the same effects as systemic administration: a firm increase in the number of spike-wave discharges (2). Lesions of the nigrostriatal dopaminergic pathways also increase the incidence of spike-wave discharges $(1,2)$. Cools and Peeters $(8)$ have shown that rats with a low functional activity of the nigrostriatal fibers show more spike-wave discharges than rats with a high functional activity (7). There is also substantial evidence that drugs with agonistic properties at dopamine receptors inhibit spike-wave discharges (11,31). Also, in humans, dopamine antagonists may induce overt seizures in patients either with a history of epilepsy or with a condition that predisposes to seizures (14). In all, these pharmacological data show that a decreased dopaminergic activity largely facilitates the occurrence of generalized spike-wave discharges. The combination of the data on catalepsy and spike-wave discharges might point toward an involvement of the dopaminergic basal ganglia in both epilepsy and catalepsy. They, further, seem to indicate that both catalepsy and spike-wave discharges are due to a hypofunction of the dopaminergic system.

In addition to the dopaminergic system, other neurotransmitter systems also have been implicated in the cataleptic state. Klemm (16) assumes that the basal ganglia and the brainstem are linked as a catalepsy system and that multiple neurotransmitter systems can be involved in regulating catalepsy, if there is a common output pathway. Certain parts of the pontine reticular system may play a role, because lesions in the pontine reticular formation prevent the expression of haloperidol- and morphine-induced catalepsy (3). Klemm (16) further assumes that various types of chemical or sensory stimulation may trigger the final common brainstem motor pathway and may induce the immobility response. One of the most puzzling phenomena in absence epilepsy is the behavioral immobility during the occurrence of generalized spike-wave activity, although the cortex, including the motor cortex, is rather activated. It can be speculated that this might be due to activation of the same brainstem mechanism that is responsible for the behavioral inactivity belonging to catalepsy.

In conclusion, this experiment presents evidence that catalepsy can be easily induced by sound stimulation in epilepsyprone rats. The sensitivity for catalepsy preceeds the presence of spike-wave discharges in the EEG of these rats by several weeks. It is thought that a dopaminergic striatal hypofunction might be involved in the pathogenesis of spike-wave discharges in WAG/ Rij rats, as well as in catalepsy.

\section{REFERENCES}

1. Buzsáki, G.; Laszlovszky, I.; Lajtha, A.; Vadasz, C. Spike-and wave neocortical patterns in rats:genetic and aminergic control. Neurosci. $38: 323-333 ; 1990$.
2. Buzsáki, G.; Smith, A.; Berger, S.; Fisher, L. J.; Gage, F.H. Petit mal epilepsy and Parkinson tremor: hypothesis of a common pacemaker. Neurosci. 36:1-14; 1990. 
3. Chesire, R. M.; Cheng, J. T.; Teitelbaum, P. The inhibition of movement by morphine or haloperidol depends on an intact nucleus reticularis tegmenti pontis. Physiol. Behav. 30:809-818; 1983.

4. Coenen, A. M. L.; van Luijtelaar, E. L. J. M. The WAG/Rij rat model for absence epilepsy: Age and sex factors. Epilepsy Res. 1:297-301; 1987.

5. Coenen, A. M. L.; Drinkenburg, W. H. I. M. ; Peeters, B. W. M. M.; Vossen, J. M. H.; van Luijtelaar, E. L. J. M. Absence epilepsy and the level of vigilance in rats of the WAG/Rij strain. Neurosci. Biobehav. Rev. 15:259-263; 1991.

6. Coenen, A. M. L.; Drinkenburg, W. H. I. M. ; Inoue, M. ; van Luijtelaar. E. L. J. M. Genetic models of absence epilepsy, with emphasis on the WAG/Rij strain of rats. Epilepsy Res. 12:75-86; 1992.

7. Cools, A. R.; Brachten, R.; Heeren, D.; Willemen, A.; Ellenbroek, B. Search after neurobiological profile of individual-specific features of Wistar rats. Brain Res. Bull. 24:49-69; 1990.

8. Cools, A. R.; Peeters, B. W. M. M. Differences in spike-wave discharges in two rat selection lines characterised by opposite dopaminergic activities. Neurosci. Lett. 134:253-256; 1992.

9. Drinkenburg, W. H. I. M; Coenen, A. M. L. ; Vossen, J. M. H.; Van Luijtelaar; E. L. J. M. Spike-wave discharges and sleep-wake states in rats with absence epilepsy. Epilepsy Res. 9:218-224; 1991.

10. Drinkenburg, W. H. I. M.; Coenen, A. M. L.; Vossen, J. M. H.; Van Luijtelaar, E. L. J. M. Sleep deprivation and spike-wave discharges in epileptic rats. Sleep 18:252-256; 1995.

11. Frey, H. H.; Voits, M. Effects of psychotropic agents on a model of absence epilepsy in rats. Neuropharmacol. 30:651-656; 1991.

12. Gattaz, W. F.; Behrens, S.; De Vry, J.; Hafner, H. Ostradiol hemmt Dopamin-vermittelte Verhaltensweisen bei Ratten -ein Tiermodell zur Untersuchung der geschlechtsspezifischen Unterschiede bei der Schizophrenie. Fortschr. Neurol. Psychiatr. 60:8-16;1991.

13. Inoue, M.; Ates, N.; Vossen, J. M. H.; Coenen, A. M. L. Effects of the neuroleptanalgesic fentanyl-fluanisone (Hypnorm) on spikewave discharges in epileptic rats. Pharmacol. Biochem. Behav. $48: 547-551 ; 1994$

14. Itil, T. M; Soldatos, C. Epileptogenic side effects of psychotropic drugs. JAMA 244:1460-1463; 1980

15. Kleinlogel, H. Spontaneous EEG paroxysms in the rat: Effects of psychotropic and alpha-adrenergic agents. Neuropsychobiol. 13:206-213; 1985.

16. Klemm, W. R. Drug effects on active immobility responses: What they tell us about neurotransmitters systems and motor functions. Progr. Neurobiol, 32:403-422; 1989.

17. Kolpakov, V. G. Catatonia in animals: Genetics, neurophysiology, neurochemistry. Novosibirsk. Nauka. 1990. (in Russian).

18. Kolpakov, V. G.; Barykina, N. N.; Chepkasov, I. L.; Alekhina, T. A.; Parvez, H. On animal models of schizophrenia. In: Parvez,
S., Nagatsu, T., Nagatsu, I., Parvez, H. eds. Methods in biogenic amine research. Amsterdam: Elsevier; 1983:997-1020.

19. Kolpakov, V. G.; Niculina, E. M.; Alekhina, T. A.; Gevorgian, M. M. Effects of neuroleptics on different types of catatonia in rats with heredity predisposition to catatonic reactions. Zhurnal Vysshei. Nervnoi. Deyatel'nosti 45:179-183; 1994. (in Russian).

20. Kostowsky, W.; Gumulka, W.; Czlonkowski, A. Reduced cataleptogenic effects of some neuroleptics in rats with lesioned midbrain raphe and treated with p-chlorophenylalaline. Brain Res. 48:443$446 ; 1972$

21. Krushinsky, L. V. The forming of animal behavior in normal and pathologic state. Moscow: Moscow University press; 1960. (in Russian ).

22. Loiseau, P. Childhood absence epilepsy, In: Roger, J., Dravet, C. Bureau, M., Dreifuss, F. E., Wolf, P., Libbey, J., eds. Epileptic syndromes in infancy, childhood and adolescence. London \& Paris: Eurotex; 1985:106-120.

23. Myslobodsky, M.; Kofman, O.; Mintz, M. Convulsant-specific architecture of the postictal behavior syndrome in the rat. Epilepsia, $22.559-568 ; 1981$

24. Peeters, B. W. M. M.; Spooren, W. P. J. M.; van Luijtelaar, E. L. J. M.; Coenen, A. M. L. The WAG/Rij model for absence epilepsy: Anticonvulsant drug evaluation. Neurosci. Res. Comm. 2:93 -97; 1988.

25. Peeters B. W. M. M.; Kerbusch J. M. L.; Coenen A. M. L.; Vossen J. M. H.; van Luijtelaar E. L. J. M. Genetics of spike-wave discharges in the electroencephalogram (EEG) of the WAG/Rij inbred strain: A classical mendelian crossbreeding study. Behav. Genetics 22:361-368; 1992

26. Petrova, E. V.; Lutchkova, T. I.; Pirozhenko, A. V. Electrocorticogram of rats with genetical catalepsy. Zhurnal Vysshei. Nervnoi. Deyatel'nosti, 42:1009-1017; 1992. (in Russian).

27. Van Luijtelaar, E. L. J. M.; Coenen, A. M. L. Two types of electrocortical paroxysms in an inbred strain of rats. Neurosci. Lett. 70:393-397; 1986.

28. Van Luijtelaar, E. L. J. M.; van der Werf, S. J.; Vossen, J. M. H; Coenen A. M. L. Arousal, performance and absence seizures in rats. Electroencephalograph. Clin. Neurophysiol. 79:430-434; 1991.

29. Van Luijtelaar, E. L. J. M.; Ates, N.; Coenen, A. M. L. Role of Ltype Calcium channel modulation in nonconvulsive epilepsy in rats. Epilepsia 36:86-92; 1995

30. Vergnes, M; Marescaux, C.; Micheletti, G.; Reis, J.; Depaulis, A. Rumbach, L.; Warter, J. M. Spontaneous paroxysmal electroclinical patterns in rat: A model of generalized nonconvulsive epilepsy. Neurosci. Lett. 33:97-101; 1982.

31. Warter, J. M.; Vergnes, M.; Depaulis, A.; Tranchant, C.; Rumbach, L.; Micheletti, G.; Marescaux, C. Effects of drugs affecting dopaminergic neurotransmission in rats with spontaneous petit-mal-like seizures. Neuropharmacol. 27:269-274; 1988. 